\title{
$\mathrm{u}-\mathrm{Health}$ 접목을 통한 자동차 Smart Space Network 환경 설계 및 구축
}

\author{
안성용 $^{1} \cdot$ 김한웅 $^{1} \cdot$ 박 $\quad$ 범 $^{1} \cdot$ 박두진 $^{2}$ \\ ${ }^{1}$ 아주대학교 산업공학과 / ${ }^{2}$ 현대-기아 자동차

\section{Apply u-Health Design and Development of Automotive Smart Space Network} \\ Sung Yong Ahn ${ }^{1}$, Han Woong Kim ${ }^{1}$, Peom Park ${ }^{1}$, Doo Jin Park ${ }^{2}$ \\ ${ }^{1}$ Department of Industrial Engineering, Ajou University, Suwon, 443-749 \\ ${ }^{2}$ Hyundai-Kia Mortors, Hwasung, 445-706
}

\begin{abstract}
In this paper ubiquitous health care system that can monitor health condition was implemented through measuring the sensor that is installed in vehicles. Implemented system consists of various wireless sensors and DB server, transmitting information that is sensed in real-time. In addition, through the sensed data based algorithm, the system which couples Web-based JSP program with Flash GUI, providing information as well as emergency service was established.
\end{abstract}

Keyword: u-Health, USN, Automotive, Sensor monitoring

\section{1. 서 론}

기술이 발달함에 따라 건강관리 시스템이 구현될 수 있는 공간에 대한 제약은 이제 하나 둘 사라지고 있다. 무선 센서 를 활용하여 가정 내에서 자유로이 측정할 수 있고 그 결 과를 의료진에게 전송하여 검진을 받을 수 있다. 이처럼 공 간에 대한 제약이 사라진 장점이 생긴 반면, 사용자에게는 다양한 선택의 자유가 부여되어 주기성, 정확성이 필수인 건강관리 시스템에 그 틈이 생겨나고 있다. 정확한 자세와 주기적인 측정을 통한 관리를 위해 태어난 재택형 건강관리 시스템은 사용자의 의지에 따라 그 주기성과 정확성이 신뢰 도를 잃어가기 때문이다. 이에 본 연구는 주거공간에서 벗어 나 현대인이 주거공간 다음으로 가장 많은 시간을 할애하는
공간, 즉 자동차에 주목하여 차량 안에서의 $\mathrm{u}-$ Healthcare 서비스 시스템을 설계 및 구축하였다.

\section{1 관련연구}

\subsubsection{USN(Ubiquitous Sensor Network)}

USN이란 필요한 곳에 센서 및 RFID 태그를 부착하고 네트워크를 구성하여 사물의 인식정보, 주변 환경정보 등의 정보를 수집하고 이를 실시간으로 네트워크를 관리하는 기 술을 말한다. USN의 핵심 기술에는 유비쿼터스 환경을 구 현하는 기술로 이루어진다. 기술 영역은 센싱, 프로세싱, 커 뮤니케이션, 인터페이스, 보안 영역으로 5 가지로 나눠진다. USN 환경을 구축하기 위해서는 5 가지 기술 영역 중에서 최 소한 센싱, 프로세싱, 커뮤니케이션 기술이 필요하다. 인터페

교신저자: 안성용

주 소: 441-192 경기도 수원시 팔달구 우만2동 76-5번지 310호, 전화: 010-3451-1616, E-mail: syahn84@gmail.com 
이스, 보안 영역은 사용자가 USN 환경을 자연스럽게 사용 가능 하도록 도와주는 영역이다(송재구, 2008). 이러한 기 술들을 활용하여 USN환경은 [표 1] 과 같은 다양한 응용분 야에 적용되고 있다.

표 1. 무선 센서 네트워크의 다양한 응용분야

\begin{tabular}{c|c}
\hline 분야 & 세부응용 \\
\hline 군사 & 군수물자, 전장감시, 지형감시, 목표물 탐지 \\
\hline 의료 & 생체 데이터 모니터링, 환자 및 의료진의 위치 탐색 \\
\hline 기상 & 온도나 기압의 측정, 재난 예보 \\
\hline 환경 & 생태계 감시, 자연 재해 방지 \\
\hline 가정 & 홈 네트워크 및 자동화 \\
\hline 회사 & 관리자동화, 지능형 사무실 \\
\hline
\end{tabular}

(윤찬영, 2600)

\subsection{2 u-Health}

최근 다양한 종류의 생체신호 측정 센서의 출현과 고성능 의 무선 통신 기기의 발전과 맞물려 시간과 장소를 뛰어넘 어 자신의 건강 상태를 항상 모니터링하고 개인화된 건강관 리 서비스를 받는 $\mathrm{u}-$ Healthcare 시대가 예고되고 있다.

\subsection{3 국외 u-Healthcare 연구동향}

미국, 일본, 유럽 등 선진국에서는 모바일, 브로드밴드, 극소형 컴퓨터, IPv6 등의 핵심 기술 등이 창출해 내는 유 비쿼터스 혁명이야 말로 새로운 정보 지식 국가 패러다임 이란 전제 아래 정부, 기업, 연구소가 유비쿼터스 시대에 $\mathrm{u}$-Healthcare 서비스가 핵심적인 서비스가 될 것으로 예 상하여 적극적인 기술 개발을 시도하고 있다.

미국의 경우, NASA, HP, MIT 등과 VivoMetrix 등에 서는 PDA나 착용식 컴퓨터(Wearable computer)와의 통신이 가능한 원격 건강진단 시스템과 스마트 액세서리 를 이용하여 생체신호를 측정 - 분석할 수 있는 LifeShirt, LifeGuard 등 착용형 또는 부착형 생체신호 감지 시스템을 개발하는 등 최신 정보통신 기술을 U-Healthcare 분야에 적용하는 시도가 이루어지고 있다. 또한, 근래에는 이러한 생체 - 의료 정보통신 응용 목적의 마이크로 소자 또는 마이 크로 시스템 개발연구 투자도 활발히 이루어지고 있다.

일본에서는 최근 북해도 대학을 중심으로 이동통신망과 위성을 통한 피부 영상 및 $\mathrm{ECG}$, 맥박 등을 전송하는 프로 젝트를 수행하고 있으며, 피부 영상의 경우 초당 20 프레임 의 영상을 전송하여 환자의 상태를 파악할 수 있는 정도의 기술에 이른 것으로 파악되고 있으나, 현재까지의 진행상황 들은 원격진료의 가능성만을 제시하고 있을 뿐, 실제적인 진 료가 행해지고 있다는 보고는 없다.

\subsection{4 국내 u-Healthcare 연구동향}

국내 u-Healthcare의 연구, 개발은 정부 각 부처에서 발 주한 u-Healthcare 관련 사업을 중심으로 활발하게 진행 되고 있다.

$\mathrm{S}$ 대 생체계측신기술센터가 과기부 지원을 받아 수행하고 있는 프로젝트에서는 인체활동을 제한하지 않고 가능한 정 상적인 생활을 유지하면서 실시간에 지속적으로 인체기능을 진단할 수 있는 생체신호계측 기술을 개발하고 있다.

산업자원부가 초고속망 사용자 수의 증가에 따라 수년 전 부터 추진하고 있는 유비쿼터스 어플라이언스 솔루션 개발 프로젝트에는 유비쿼터스 지원 무선 네트워크 칩 세트, 스 마트 - 네트워크 부가 모듈, 유비쿼터스 지원 네트워킹 미들 웨어 및 의료/건강 솔루션 기술을 포함한 유비쿼터스 응용 솔루션 기술 개발이 포함되어 있다.

산업계에서도 $u$-Healthcare 관련 기술을 개발하고 제품 을 출시하고 있다. 한국정보통신대학교(ICU)에 설립된 $\mathrm{S}$ 기 업 산학공동연구센터의 $\mathrm{u}$-Healthcare 연구팀에서는 휴대 폰을 매개로 한 $\mathrm{u}$-Healthcare 서비스 플랫폼에 관한 연구 와 ECG, 스트레스, 비만, 혈당 등의 $\mathrm{u}$-Healthcare 응용 프로그램 개발을 수행하고 있다. L기업에서는 최근 헬스피 아와 공동으로 스트레스 및 혈당 센서를 휴대폰에 내장시켜 국내 시장에 출시하기도 하였다(한동수, 2006).

\section{2. 본 론}

\section{1 시스템 개요}

본 연구의 시스템은 기존의 건강관리 시스템과는 달리 차 량에 적용된 $\mathrm{u}$-Healthcare 서비스 시스템이다. 기존의 가 정이나 병원에서 사용자 스스로가 정적인 상태에서 관리하 는 건강관리 시스템이라면, 본 시스템은 차량이라는 특수한 공간안에 운전자의 동적인 상태에서도 실시간 자동 모니터 링 되는 시스템이다.

체온 센서와 대기 센서는 실시간으로 측정되며, 맥박 센서 는 운전자가 접촉을 통해 측정하게 된다. 측정된 데이터는 기존 네비게이션관 같이 개발된 차량 Flash GUI(그림 6) 를 통해 제공된다.

\section{2 센서 모니터링 시스템 구성}

\subsection{1 시스템 구성요소}

본 연구에서 제안한 센서 모니터링 시스템의 하드웨어적, 소프트웨어적 구성요소는 [표 2] 과 같다. 
표 2. 센서 모니터링 시스템 구성요소

\begin{tabular}{c|c|c}
\hline $\begin{array}{c}\text { Disturbance } \\
\text { Term }\end{array}$ & 구성요소 & 구성내용 \\
\hline \multirow{4}{*}{ H/W } & Local Server & Laptop PC \\
\cline { 2 - 3 } & Zigbee & Hmote-ZigBee Board \\
\cline { 2 - 3 } & Sensor & $\begin{array}{c}\text { PulseOximeter 모듈 } \\
\text { 적외선 온도 센서 } \\
\text { 대기 센서 모듈 }\end{array}$ \\
\cline { 2 - 3 } & Display & 8인치 터치 스크린 \\
\hline \multirow{5}{*}{ S/W } & Operating & TinyOS \\
& System & Window XP \\
\cline { 2 - 3 } & Language & JAVA / JS \\
& Database & FySQ \\
\cline { 2 - 3 } & Web Server & Apache Tomcat 6.0 \\
\cline { 2 - 3 } & &
\end{tabular}

\subsection{2 하드웨어 구성요소}

하드웨어 적인 부분의 시스템 구성요소에는 수신 Zigbee Board의 연결, 디스플레이 장치의 연결, 전체적인 데이터를 저장하는 데이터베이스 및 기타 소프트웨어적인 연결을 위 한 Local Server로 Laptop PC를 사용하였다. 자동차라는 공간적인 특성을 고려하여 좁은 공간에 위치시키기 쉽기 때 문에 Laptop PC를 사용하였다.

[그림 1] 의 Zigbee Board는 Hmote라는 기본보드에 센서 보드를 장착시켜 무선 센서로 사용하고 센서보드를 장착시 키지 않을 경우 센서보드에서 전송되는 데이터를 수신하는 수신보드로 사용하여 Local Server에 연결한다. 본 연구에 서 사용된 센서보드들은 [그림 2] 의 센서들을 사용하였다.

본 연구에서 측정을 하는 센서신호는 맥박, 체온, 대기 상 태이다. 맥박 센서는 Pulse Oximeter 모듈로 빛의 반사를 통해 맥박, 혈중산소농도를 측정 한다. 온도 센서는 적외선 센서를 사용하여 표면 온도를 측정하고 표면 온도를 측정하

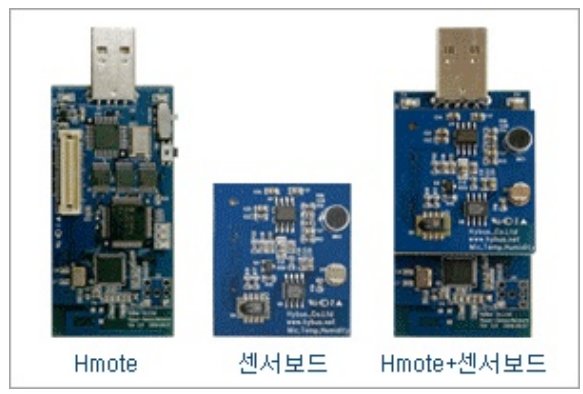

그림 1. Zigbee Board
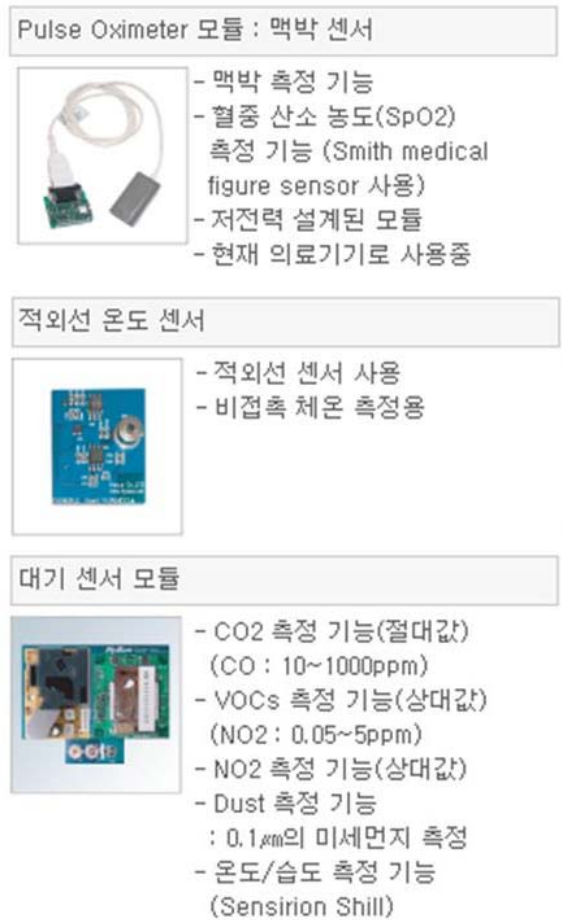

그림 2. 환경 측정 센서

여 비접촉식으로 체온을 측정할 수 있다. 대기 센서는 $\mathrm{CO}_{2}$, $\mathrm{VOCs}, \mathrm{NO}_{2}$, 먼지, 온도/습도의 측정이 가능하여 실내 대기 상태를 알 수 있다.

\subsection{3 소프트웨어 구성요소}

기본적으로 센서들을 관리하기 위한 운영체제는 TinyOS 를 사용한다. TinyOS는 버클리 대학에서 센서를 활용하기 적합한 환경을 위해 개발하였고, 각 센서들의 기능에 따른 데이터를 변환하는 기본 소스들도 개발되었다(강경옥 외, 2006). TinyOS 안에 기본적으로 JAVA소스들이 설정되어 있어서 JAVA로 연동할 수 있고 관리가 용이한 MySQL로 데이터베이스를 구성하였고, 웹 서버로는 JSP와 활용이 용 이한 Apache Tomcat을 사용하였다. 웹 프로그램인 JSP를 활용하여 데이터베이스에 저장된 센싱 데이터들을 불러오고 Flash GUI와 연동 가능하도록 데이터를 보내준다. Flash

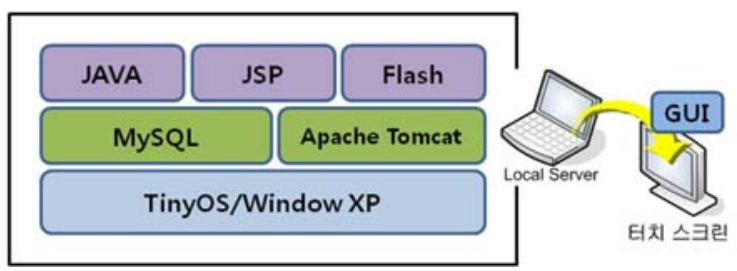

그림 3. S/W 구조 
프로그램에서 JSP에서 불러온 데이터베이스의 데이터를 가 져가기 위해서는 JSP 소스 내에 [표 3] 과 같이 출력을 해 주어야 한다. 소스코드 중 ' $\&$ ' 기호를 통해 추출할 데이터를 구분하여 추출한다.

\section{표 3. JSP, Flash 데이터 연동}

\section{out.print ("\&pulse=65\&spo2=150\&");}

\section{3 시스템 구현}

\subsection{1 시스템 환경 구축}

실제 자동차에 구현된 상태는 [그림 4]와 같이 구성되었 다. 센서들은 각각 맥박, 혈중산소농도, 체온, 대기 값들을 수집하고 Zigbee 무선 통신 방식으로 서버로 전송하는 기 능을 담당하고 서버에 연결되어 있는 Hmote에서 각 센서들 의 신호를 수신하는 기능을 담당한다. 자동차 내에 각 센서 들의 설치 위치는 센서의 특성을 고려하여 설치하였다. 맥 박 센서는 손가락을 직접 접촉해야 하기 때문에 가장 접근 을 쉽게 할 수 있는 스티어링휠 뒷부분에 설치하였다. 온도 센서는 비접촉식 측정을 한다. 신체 부위 중 항상 노출이 되 어 비접촉식으로 측정할 수 있는 부분은 인체 안면부분이기 때문에 안면을 가장 비추기 좋은 위치인 썬바이저 윗부분에 설치하였다. 대기 센서는 자동차 루프의 중앙에 위치한 조명 등 근처에 설치하였다.

Local Server에는 모든 소프트웨어가 설치되어 있어 Hmote에서 수신된 신호를 JAVA 프로그램을 통해 변환하 여 데이터베이스에 저장하고 Flash GUI에 출력하기 위하여 $\mathrm{JSP}$ 를 통해 데이터베이스에서 저장된 데이터들을 실시간으 로 추출해온다. 데이터 값은 실시간으로 저장되고 실시간으 로 추출되어 출력된다. 출력되는 Flash GUI 화면은 Local Server 모니터에 출력되는 화면과 같은 화면을 디스플레이 장치로 출력해준다. 디스플레이 장치는 터치 스크린으로 네 비게이션을 이용하는 방식과 같은 방식으로 Flash GUI를 사용할 수 있다.

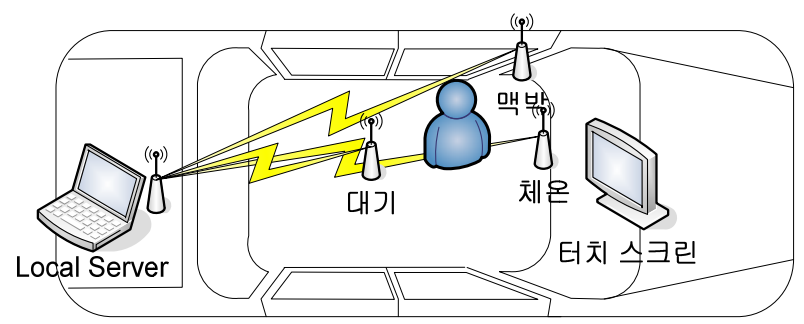

그림 4. Zigbee 무선 통신 구조

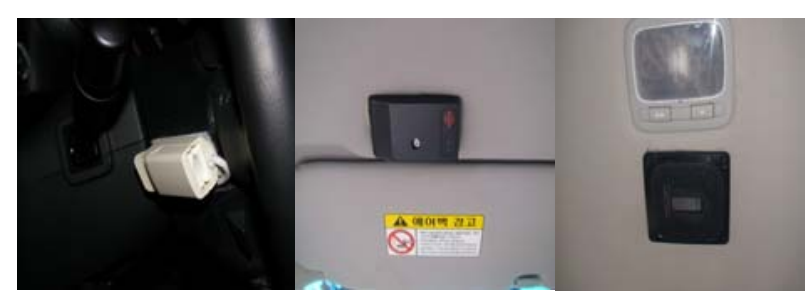

그림 5. 실제 센서 설치 모습

\subsection{2 시스템 시나리오}

본 연구에서 설계된 시스템을 실제 사용하는 시나리오는 다음과 같다. 운전자가 탑승을 한 후부터 온도 센서와 대기 센서는 계속적으로 센싱을 한다. 맥박 센서는 운전자가 자동 차 내에서 언제든지 센서에 접촉을 하면 센싱하여서 체크가 된다. 측정되어지는 데이터들이 정상 범위의 데이터일 경우 에는 Flash GUI(그림 6 차량 Flash GUI)의 메인화면에서 세 개의 데이터를 bar 형식으로 현재의 상태를 보여준다. 체크 중에 이상 데이터가 발생하였을 경우에는 해당 센서의 페이지로 이동하여 실제 수치 데이터와 함께 보여진다. 페이 지가 바뀌면서 자동적으로 경고음이 울리고 현재 이상 상태 라는 것을 알려준다. 이상 상태가 지속될 경우에는 맥박, 체 온의 경우에는 자동차의 비상등이 깜빡이고 대기의 경우에 는 자동적으로 창문이 열리게 된다. 이상 상태에서 정상으로 돌아오면 비상등이 꺼지고 창문은 다시 자동적으로 닫힌다.

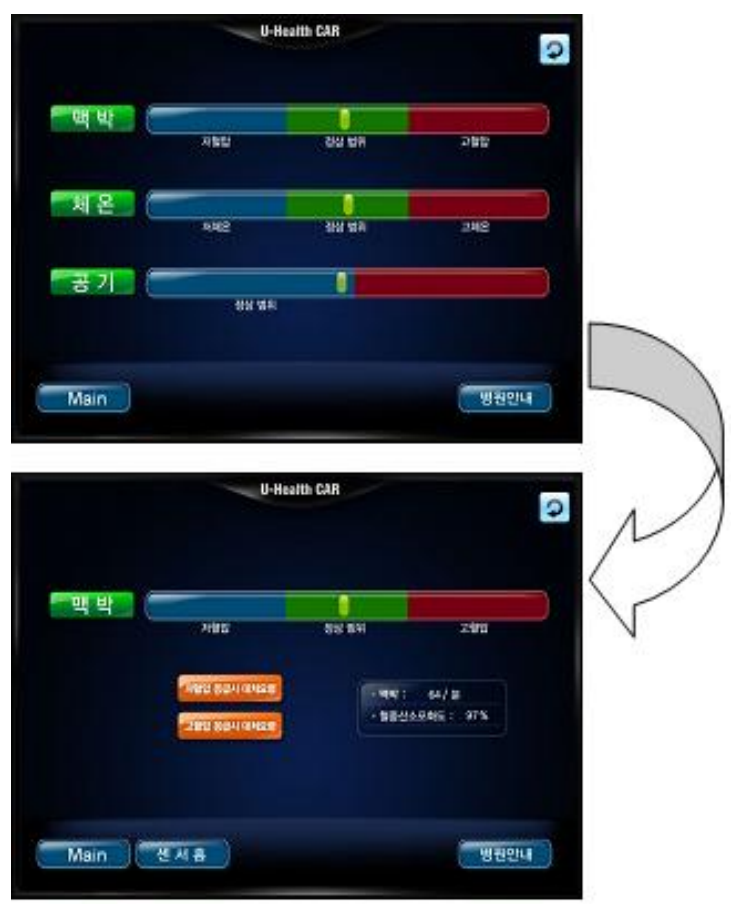

그림 6. Flash GUI 


\section{3. 결 론}

본 연구에서는 USN 환경을 이용하여 차량에 장착된 생체 의료 센서 측정을 통한 자동차 공간안에서의 건강 상태를 체크할 수 있는 유비쿼터스 헬스케어 시스템을 설계 및 구 현하였다.

구현된 시스템은 체온 센서, 맥박 센서, 대기 센서, 중 앙 MySQL DB 서버로 구성된다. 센서 단말기는 지그비 (Zigbee) 프로토콜로 센서 네트워크를 구성하며 TinyOS 기반으로 이루어진 초소형 보드로 설계되었다. 센싱 데이터 수신 중앙 서버는 MySQL DB로 구성되어 무선으로 센싱된 정보를 실시간으로 전송한다. 또한 $\mathrm{DB}$ 알고리즘을 통하여 웹 기반의 JSP 프로그램과 Flash Gui와 연동하여 정보를 제공하였다. 기본적인 서비스와 System 구성을 실험적으 로 구축하였고 자동차 공간을 $\mathrm{u}-\mathrm{Health}$ 서비스가 가능한 Smart Space로 확장할 수 있는 기반을 마련했다.

하지만 센서 (맥박, 체온, 대기) 들은 차량용 센서들이 아니 라 기존의 센서들을 사용하여 구현되어 상황에 따라 실제 값과는 다르게 측정되는 한계가 있다. 이 한계에 대해서는 추후에 차량용 센서 개발연구가 진행되어야 한다.

또한 Healthcare에 대한 관심과 기술력은 전 세계적으로 커지고 있다. 다양한 시범 사업을 통해 Healthcare에 대한 기술력을 확보하고 있는 시점에서, 앞으로 국내 자동차 및 Healthcare 시장을 주도하기 위해 아직 미흡한 인체 센싱 센서 기술에 대한 연구와 차량용 센싱 기술, 센서 네트워크 및 각 관련 기관들의 적극적인 연구와 표준화 참여가 필요 하다.

\section{참고 문헌}

송재구, uHealthcare 서비스를 위한 USN 상황인식 시스템 연구, 한남대학교 대학원, 2008

윤찬영, USN 환경에서 U-Healthcare Monitoring System 구현, 광운대 학교 대학원, 2006.

강경옥, 김용우, 권훈, 김부림, Tiny-DB와 MySQL을 이용한 유비 쿼터스 센서 네트워크 기반의 실시간 정보 서비스 설계 및 구현, 한국산학기술학회, 7(2), 175-181, 2006.

김정원, 센서네트워크에 기반한 유비쿼터스 헬스케어 시스템의
설계 및 구현, 한국컨텐츠학회, 8(1), 143-151, 2008.

유주현, 송길종, 유남현, 양수영, 김원중, 유비쿼터스 센서를 이용 한 농작물 관리 시스템의 설계 및 구현, 한국인터넷정보학회, 9(2), 417-420,2008.

Dongsoo, Han., et al. "모바일 e-Health 서비스 시스템 연구보고서", 한국정보통신대학교, 2006. 3.

지경용, 김문구, 박종현, 오동섭, 정우소, "신규 u-Health 비즈니스 모델 개발을 위한 시장수요 분석 보고서:, 기획보고서 05-17, 한국전자통신연구원, 2005.

u-Healthcare: New Paradigm in Medicine, u-Healthcare Symposium, 2006. 2.

Dongsoo, Han., Sunjoon, Park and Smita, Kurkuri., "An Evolving Mobile E-Health Service Platform," 1st International Conference on Design Science Research in Information Systems and Technology, Feb. 2006.

\section{저자 소개}

* 안 성 용 syahn83@gmail.com 아주대학교 산업정보시스템공학부 학사 현 재: 아주대학교 산업공학과 석사 관심분야: Automotive, Ergonomics, HCI, UI

* 김 한 웅 hanationbear@gmail.com 아주대학교 산업정보시스템공학부 학사 현 재: 아주대학교 산업공학과 석사 관심분야: Ergonomics, $\mathrm{HCI}$

\section{* 박 범 * ppark@ajou.ac.kr \\ IOWA State Univ. HCI \\ 현 재: 아주대학교 산업공학과 교수 \\ 관심분야: Ergonomics, $\mathrm{HCI}$
* 박 두 진 pdjsmk@hyundai-motor.com 한양대학교 전기공학과 석사 현 재: 현대자동차 연구원 관심분야: Automotive Electronics

논 문 접 수 일 (Date Received) : 2009년 08월 26일 논 문 수 정 일 (Date Revised) : 2009년 11월 27일 논문게재승인일 (Date Accepted) : 2009년 11월 30일 